\title{
Nerve agents: emergency preparedness
}

\author{
Alan George Andrew Weir 이, 1,2 S Makin (10), J Breeze (1) 3,4
}

${ }^{1}$ Emergency Department, Basingstoke and North Hampshire Hospital, Basingstoke, UK

${ }^{2}$ Army Medical Services, Camberley, UK

${ }^{3}$ Royal Centre for Defence Medicine, Birmingham, UK ${ }^{4}$ Department of Maxillofacia Surgery, Queen Elizabeth Hospital Birmingham, Birmingham, UK

\section{Correspondence to}

J Breeze, Royal Centre for Defence Medicine, Birmingham B15 2SQ, UK; editor. bmjmilitary@bmj.com

Received 21 November 2019 Accepted 23 November 2019

Check for updates

(c) Author(s) (or their employer(s)) 2020. No commercial re-use. See rights and permissions. Published by BMJ.

To cite: Weir AGA, Makin S, Breeze J. BMJ Military

2020:166:42-46.

\section{ABSTRACT}

Nerve agents (NAs) are a highly toxic group of chemical warfare agents. NAs are organophosphorus esters with varying physical and chemical properties depending on the individual agent. The most recently developed class of NA is 'Novichok', the existence of which was first revealed in the early 1990s, just before Russia signed the Chemical Weapons Convention. In 1984, Iraq became the first nation to deploy NA on the battlefield when they used tabun against Iranian military forces in Majnoon Island near Basra. The first terrorist use of an NA is believed to be the attack in Matsumoto, Japan, on 27 June 1994 by the Aum Shinrikyo doomsday cult. Symptoms and ultimate toxicity from NA poisoning are related to the agent involved, the form and degree of exposure, and rapidity of medical treatment. The classic toxidrome of significant exposure to NA comprises bronchorrhoea, bronchospasm, bradycardia and convulsions, with an onset period of as early as a few seconds depending on the mode and extent of exposure. If medical management is not instituted rapidly, death may occur in minutes by asphyxiation and cardiac arrest. In the UK, emergency preparedness for NA poisoning includes an initial operational response programme across all blue light emergency services and key first responders. This paper describes the development, pathophysiology, clinical effects and current guidance for management of suspected NA poisoning. It also summarises the known events in which NA poisoning has been confirmed.

\section{INTRODUCTION}

Nerve agents (NAs) are a particularly toxic group of chemical warfare agents. ${ }^{1}$ They are chemically related to the organophosphate pesticides, although their clinical presentation and medical management may vary from that of organophosphate poisoning, dependent on which agent is involved. ${ }^{1}$ NAs are inhibitors of acetylcholinesterase (AChE), and it is the resulting accumulation of acetylcholine (ACh) that produces the signs and symptoms of NA poisoning. ${ }^{12}$ Symptoms and ultimate toxicity from NA poisoning are related to the agent involved, the form and degree of exposure, and rapidity of medical treatment. The classic toxidrome of significant exposure to NA comprises bronchorrhoea, bronchospasm, bradycardia and convulsions, with an onset period of as early as a few seconds depending on the mode and extent of exposure. If medical management is not instituted rapidly, death may occur in minutes by asphyxiation and cardiac arrest. ${ }^{3}$ The effects of NA poisoning, where death does not occur, have been shown to be long-lasting and cumulative (repeated exposures to NA) in nature, with survivors sustaining chronic neurological damage and psychiatric sequelae. ${ }^{124-6}$ NAs were first developed in Germany prior to and
Key messages

- Nerve agents (NAs) are organophosphorus esters with varying physical and chemical properties depending on the individual agent.

- The severity and onset of the effects of NA poisoning are dependent on the agent, the route of exposure and the total amount of agent absorbed.

- The management of NA poisoning consists of pretreatment, recognition of poisoning, medical management, decontamination and prevention of secondary casualties.

during the Second World War, with further development continuing into the Cold War era, although there is no recorded military deployment during these periods. In the modern era there have been confirmed deployments of NA in Iraq, ${ }^{7}$ Japan, ${ }^{8}$ Syria, ${ }^{9}{ }^{10}$ Malaysia $^{11}$ and more recently in the UK. ${ }^{12} 13$

\section{AGENT DEVELOPMENT}

NAs were first discovered by German scientist Gerhard Schrader while he was working on insecticides for IG Farben in $1936 .{ }^{14}{ }^{15}$ At that period in history the Nazi regime in Germany had decreed that all scientific advances that could be of military significance were to be reported to the authorities. This resulted in a sample of a highly toxic pesticide, discovered by Gerhard Schrader, coming to the attention of the chemical weapon section of the German Army Weapons Office. Following this, multiple laboratories were established to pursue this new line of weapon development. The first NA produced was tabun, which was quickly followed by sarin, soman and cyclosarin. This first class of NAs is known as the ' $G$ ' agents, named by the Americans when they discovered this weapon programme: ' $G$ ' stands for 'German Agent', for example, tabun is GA (German agent A), sarin is GB, soman is GD and so on. ${ }^{15}$ These agents were successfully kept secret until the closing stages of the Second World War, and while Germany militarised these agents for use there is no record of them having ever been deployed against Allied Forces. By the mid-1950s a second class of NAs had been developed and was known as the ' $V$ ' agents (for venomous) in American nomenclature. ${ }^{15}$ ' $V$ ' agents, such as VX, are much more stable than the ' $G$ ' agents and are approximately tenfold more poisonous, making them among the most toxic substances ever synthesised. ${ }^{15}$

Most chemical weapon munitions can be described as unitary in that each munition contains the toxic, ready-to-use chemical agent. ${ }^{15}$ Binary technology was invented in which a munition 
contains two separate and relatively inert substances that when combined, en route to a target, will form the toxic agent. ${ }^{15}$ This results in materials that are much safer to produce, transport, store and destroy. ${ }^{15}$ Sarin (GB-2), soman (GD-2) and VX (VX-2) have all been militarised in this manner. ${ }^{15}$ The most recently developed class of NAs is 'Novichok', the existence of which was first revealed in the early 1990s, just before Russia signed the Chemical Weapons Convention. ${ }^{16-18}$

In 1984, Iraq became the first nation to deploy NA on the battlefield when they used tabun against Iranian military forces in Majnoon Island near Basra. ${ }^{17}$ Tabun and sarin were used on more occasions against Iranian forces. ${ }^{19}$ On 16 March 1988, the Iraqi regime launched an attack against the Kurdish village of Halabja using sarin and mustard gas, which is believed to have killed between 3200 and 5000 people. $^{72021}$ The first terrorist use of an NA is believed to be the attack in Matsumoto, Japan, on 27 June 1994 by the Aum Shinrikyo doomsday cult. A refrigerated truck was used to release a cloud of sarin gas, affecting approximately 600 people with seven fatalities, all dying prehospital. Of the casualties admitted to hospital, there were no fatalities. ${ }^{822} 23$ In 1995 the same cult deployed sarin in an even larger terrorist attack on the Tokyo subway system, exposing over 6000 people and resulting in 12 deaths. $^{22}$ Since the Chemical Weapons Convention in 1997, there have been a number of instances of use of NA. The Organisation for the Prohibition of Chemical Weapons-United Nations Joint Investigative Mechanism confirmed that the Syrian Arab Republic government was responsible for the release of sarin at Khan Shaykhun on 4 April 2017 during the ongoing civil war. ${ }^{24}$ The largest event occurred on 21 August 2013, when rockets were used to deliver sarin to a population within Damascus, which is believed to have resulted in at least 350 fatalities. ${ }^{9}$ On 13 February 2017, VX was used by the North Korean regime in an airport in Malaysia to assassinate the brother of Kim Jong-Un, head of the North Korean regime. ${ }^{11}$ On 4 March 2018, a novichok NA was deployed in Salisbury, UK by the Russian military intelligence service, still commonly known as the Glavnoye Razedyvatel'noye Upravleniye(GRU). The casualties first identified were Sergei Skripal, a former Russian Military Intelligence Officer, his daughter Yulia, plus a UK police officer, one of the first emergency service responders to the incident, who was also contaminated. Another victim, a second police officer, was identified in 2019 following further forensic tests. Two further individuals were later exposed to the same novichok NA in Amesbury, UK, one of whom died as a result. $^{1213}$

\section{CHEMICAL PROPERTIES}

NAs are organophosphorus esters that, like most chemicals, have varying physical and chemical properties depending on the individual agent. Generally, in the pure state NAs are colourless and mobile liquids, whereas in the impure state they may have a yellowish to brown colour, and some NAs may have a slightly fruity odour. The ' $G$ ' class of agents tends to be non-persistent, whereas the ' $V$ ' agents tend to be persistent, although many NAs can be thickened to increase their persistence. The non-persistent agents are volatile liquids at room temperature that give rise to vapour and would be used to produce a 'cloud' of NA. In general, NAs are moderately soluble in water with slow hydrolysis, highly soluble in lipids, and are rapidly inactivated by strong alkalis and chlorinating compounds.

\section{MECHANISM OF ACTION}

NAs may be absorbed through any of the body's surfaces, the rapidity with which effects occur is directly related to the amount of NA absorbed in a given time period. The principal effect of NA within the body is to inhibit AChE, although there are other enzymes within the cholinesterase family which are also affected, for example, butyrylcholinesterase. The normal function of AChE is to hydrolyse ACh wherever it occurs in the body; therefore, NA exposure results in an accumulation of ACh at its various sites of action with a subsequent prolongation of the normal expected action. These sites include the endings of the parasympathetic nerves to the smooth muscle of the iris, ciliary body, bronchial tree, gastrointestinal tract, bladder and blood vessels; to the salivary glands and secretory glands of the gastrointestinal tract and respiratory tract; and to the cardiac muscle and endings of sympathetic nerves to sweat glands. The accumulation of $\mathrm{ACh}$ at these sites results in the characteristic muscarinic signs and symptoms. Accumulation of ACh at the endings of motor nerves to voluntary muscles and in some autonomic ganglia results in nicotinic signs and symptoms. The inhibition of cholinesterase enzymes throughout the body by NAs may be irreversible and its effects prolonged.

\section{CLINICAL EFFECTS}

The severity and onset of the effects of NA poisoning are dependent on the agent, the route of exposure, and the total amount of agent absorbed. NA has effects on many systems, each with their own specific symptoms. Therefore, the symptoms displayed by a casualty exposed to NA will vary depending on the degree to which each system is affected; hence, there may not be one simple toxidrome presenting among casualties of NA poisoning, but rather a combination of different symptoms.

\section{Local ocular effects}

These appear within seconds or minutes from exposure to vapour or liquid to the eye, and before there is any evidence of systemic absorption. The NA effects on the smooth muscle of the eye result in marked miosis (pupillary constriction), pain in and behind the eyes from ciliary spasm, some difficulty of visual accommodation, and frontal headache. Pain becomes worse on trying to focus the eyes or on looking at bright light. Some twitching of the eyelids may occur, and in the absence of systemic absorption there may be nausea and vomiting secondary to these ocular symptoms. Conjunctival hyperaemia also occurs. These symptoms may persist for several weeks following exposure to a large dose of NA.

\section{Local respiratory effects}

Following minimal exposure, the earliest effects on the respiratory tract are watery nasal discharge, nasal hyperaemia, sensation of tightness in the chest and occasionally prolonged wheezing suggestive of bronchoconstriction or increased bronchial secretions. These symptoms may last for several days depending on the degree of exposure.

\section{Local gastrointestinal effects}

Following the ingestion of substances containing an NA (which is essentially tasteless), the initial symptoms will include abdominal cramps, nausea, vomiting and diarrhoea. If the casualty has been exposed to sufficient NA, systemic symptoms will develop.

\section{Systemic effects}

The sequence of symptoms varies with the route of exposure. Respiratory symptoms are generally the first, and most severe, to 
appear after inhalation of NA vapour, and it is likewise for gastrointestinal symptoms following ingestion. Otherwise, systemic manifestations are, in general, similar after any exposure to NA by any route. If local ocular exposure has not occurred, ocular manifestations may initially be absent, with mydriasis occurring following systemic absorption due to the nicotinic effect on the superior cervical ganglion. Pupillary dilation may occur as part of the systemic effects, which may also further distinguish the nicotinic and muscarinic effects. The systemic effects may be considered to be muscarinic, nicotinic or central. The predominance of muscarinic, nicotinic or central nervous system effects will influence the therapy the casualty requires. Acute or delayed (up to 50 hours postexposure) pulmonary oedema has been described following pesticide poisoning. The exact mechanism is unknown and may be secondary to a direct cardiac effect, haemodynamic modification or both.

\section{Muscarinic effects}

Bronchoconstriction occurs and may result in coughing, wheezing and respiratory distress as ventilation becomes difficult. Bronchorrhoea with thick tenacious secretions add to airway obstruction. Excessive salivation with profuse watery secretions pouring from the mouth may be seen. Laryngeal spasm followed by collapse of the hypopharyngeal musculature may add to airway obstruction. The casualty may be seen gasping for breath, frothing at the mouth and becomes cyanotic. As hypoxaemia and cyanosis increase, the casualty will fall exhausted and become unconscious, with cardiac arrest imminent. Death may occur in minutes from significant inhalational exposure. However, if exposure is not enough to cause rapid death, other muscarinic effects may appear. These include sweating, nausea, and epigastric and substernal tightness with heart burn and eructation. If absorption of NA has been great enough (whether due to a single large exposure or to repeated small exposures), there may follow abdominal cramps, increased peristalsis, vomiting, diarrhoea, tenesmus, increased lacrimation and urinary frequency. Cardiovascular effects may include bradycardia, hypotension and arrhythmias. Profuse perspiration, involuntary defaecation and urination may all occur, which in turn may lead to circulatory collapse and cardiorespiratory arrest.

\section{Nicotinic effects}

Symptoms begin with increased fatigue and mild generalised weakness that is exacerbated by exertion. Involuntary muscular twitching, scattered muscular fasciculations and muscle cramps follow. Vasoconstriction results in pale skin and tachycardia can occur. With severe exposure muscle fasciculations become generalised and 'rippling' movements can be seen under the skin and twitching occurs in all parts of the body. Generalised muscular weakness progresses until the muscles of respiration are affected, resulting in respiratory depression and ultimately respiratory arrest.

\section{Central nervous system effects}

Mild NA exposures result in anxiety, jitteriness, restlessness, emotional lability, insomnia or excessive dreaming with nightmares. Headache, tremor, drowsiness, poor concentration, memory and recall impairment, and slowing of reactions may occur. A greater exposure can result in confusion and ataxia. The casualty may become comatose, reflexes may disappear, respiration may become impaired and Cheyne-Stokes in nature, and generalised seizures may ensue. Death is usually due to respiratory arrest and anoxia, although depression of circulatory centres can occur with marked bradycardia and hypotension.

\section{Cumulative effects}

Repeated exposure to very small concentrations of NA that are insufficient to result in clinical symptoms may result in the onset of symptoms. Continued exposure will result in increasingly severe effects. This susceptibility may last for several months as new AChE is slowly synthesised to replace that which is already degraded. This increased susceptibility is not limited to the particular NA, but rather any NA or other cholinesterase inhibitor will have the same cumulative effects.

\section{Potential long-term effects}

Minor electroencephalogram (EEG) changes have been noted in those exposed to NA more than one year following exposure. Neuropsychiatric changes have been noted in individuals for weeks to months after organophosphate poisoning. Follow-up of survivors of the Tokyo sarin attack demonstrated memory loss at two years ${ }^{5}$ and slight differences in motor performance at seven years. ${ }^{6}$

\section{MANAGEMENT OF NA POISONING}

The management of NA poisoning consists of pretreatment, recognition of poisoning, medical management, decontamination and prevention of secondary casualties.

\section{Pretreatment}

The treatment of poisoning by NAs, which rapidly form ageing agent-enzyme complexes, is particularly difficult. Ageing is the biochemical process by which the agent-enzyme complex becomes resistant to reactivation, and in effect the AChE has been rendered $100 \%$ inactive. For example, in the case of soman, the agent-enzyme complex ages within minutes, making it highly lethal. To counter this, pretreatment with carbamates can be used. Once a casualty has been poisoned with NA, this will result in a constant return of AChE to the neurovascular system in order to help counter the effects of ACh accumulation, provided there is no ongoing exposure to NA. There are no significant side effects from pretreatment as the inhibition of AChE by carbamates is a slower process than in NA poisoning, and there is negligible inhibition of central ACh. Once NA poisoning has occurred, however, pretreatment must cease and postexposure treatment commenced, otherwise the casualty will be doubly poisoned by the NA and carbamate inhibiting AChE.

\section{Postexposure treatment}

The principle of postexposure treatment is early pharmacological therapy with good general supportive care, which may include critical care interventions such as orotracheal intubation and ventilation, and cardiovascular support in an Intensive Care Unit (ICU) setting. Atropine is essential, and its mechanism of action is to block the effects of ACh at the muscarinic receptors, while having little effect on nicotinic receptors. At high doses it may also help reduce central respiratory depression and have some anticonvulsant action. Very high total doses of atropine may be required and may need to be administered every few minutes, ideally intravenously, but subcutaneous and intramuscular administration may be used. Signs that successful atropinisation is occurring include decreased bronchospasm, drying up of secretions and normalisation of HR.

Oximes are able to reactivate NA-AChE complexes that have not aged, thereby antagonising the effects of the NA by freeing up AChE. In severe poisoning, as for atropine, repeated doses of oxime may be attempted, but if there is no clinical effect then 
there is little benefit to continued administration. Oximes and atropine are synergistic in their effects.

\section{DECONTAMINATION AND PREVENTION OF SECONDARY CASUALTIES}

The most important aspect of managing casualties of NA poisoning is recognising that NA is responsible for the casualties. Clearly recognising this will allow appropriate medical management to be initiated, but more importantly it will allow for the prevention of secondary casualties. As already discussed, NA can be deployed by various means in different forms. If the casualty is contaminated, rescuers and first responders face the very real risk of being exposed to NA themselves and becoming casualties. Furthermore, if casualties are transported to another site, the risk of secondary casualties is greatly increased, plus there is the possibility of unknowingly contaminating others who may disperse from the scene before they show signs of toxicity. Therefore, containment and decontamination of casualties and the scene are required. The ease and rapidity at which this occurs will be dependent on the particular scenario in question.

\section{EMERGENCY PREPAREDNESS}

In the UK there is an initial operational response (IOR) programme across all blue light emergency services and key first responder, which aims to improve patient outcomes following contamination with hazardous materials (HAZMAT) or a chemical, biological, radiological or nuclear (CBRN) incident. ${ }^{25-27}$ A key element of the IOR is the recognition of a HAZMAT or CBRN incident by first responders. The 'STEP 1-2-3+ process $^{26} 28$ serves as a safety trigger for emergency personnel attending collapsed persons.

\section{Step 1: one casualty}

- Approach using normal procedures: CBRN contamination unlikely.

\author{
Step 2: two casualties \\ - Approach with caution, consider all options. \\ - CBRN contamination possible. \\ - Report on arrival, update control. \\ - If possible or suspected, follow advice for step 3.
}

\section{Step 3: three casualties or more}

- Do not approach the scene: CBRN contamination likely.

- Identify hazards.

- Control the scene.

- Give methane report as soon as possible. Direct ambulant casualties to place of safety.

- Make risk assessment and provide help to non-ambulant casualties if benefit outweighs risk using minimum personnel and appropriate personal protective equipment (PPE).

The guidance on PPE has changed from previous versions. Only specialist responders beyond the IOR are now always required to wear PPE. The purpose of the revised IOR is to enable none specialists without PPE to carry out initial life-saving and recovery-promoting activities. The Public Health England document 'Chemical, biological, radiological and nuclear incidents: clinical management and health protection ${ }^{26}$ details how the scene of a CBRN incident should be managed and provides guidance on the management of casualties from the scene with particular emphasis on decontamination. This guidance was supplemented by specific advice to emergency departments in
July 2018 on the specific management of suspected Novichok poisonings. ${ }^{27}$ Specialised detection systems exist to aid identification of NA as the causative agent in CBRN incidents. Detector papers that change colour in the presence of liquid NA may be used. ${ }^{1} \mathrm{~A}$ variety of detectors and monitors for use in surveying the environment are available and may be used by the military and civilian specialist response units. ${ }^{1}$

Acknowledgements The authors wish to acknowledge the paper 'Nerve Agents, Journal of the Royal Army Medical Corps 2002; 148:344-357', which served as a base of information for this manuscript.

Contributors All authors contributed to the conception, research and writing of the manuscript. All authors have approved the final manuscript.

Funding The authors have not declared a specific grant for this research from any funding agency in the public, commercial or not-for-profit sectors.

Competing interests None declared.

Patient consent for publication Not required.

Provenance and peer review Commissioned; internally peer reviewed.

Data availability statement No data are available.

\section{ORCID iDs}

Alan George Andrew Weir http://orcid.org/0000-0002-3347-1701

S Makin http://orcid.org/0000-0003-4137-4095

J Breeze http://orcid.org/0000-0002-2352-1365

\section{REFERENCES}

1 Anon. Nerve agents. J R Army Med Corps 2002;148:344-57.

2 Colović MB, Krstić DZ, Lazarević-Pašti TD, et al. Acetylcholinesterase inhibitors: pharmacology and toxicology. Curr Neuropharmacol 2013;11:315-35.

3 ATSDR. Medical management guidelines (MMGs): nerve agents (GA, GB, Gd, VX). Available: www.atsdr.cdc.gov/mmg/mmg.asp?id=523\&tid=93 [Accessed $23 \mathrm{Mar}$ 2108].

4 Sidell FR. Soman and sarin: clinical manifestations and treatment of accidental poisoning by organophosphates. Clin Toxicol 1974;7:1-17

5 Nishiwaki Y, Maekawa K, Ogawa Y, et al. Effects of sarin on the nervous system in rescue team staff members and police officers 3 years after the Tokyo subway sarin attack. Environ Health Perspect 2001;109:1169-73.

6 Hoffman A, Eisenkraft A, Finkelstein A, et al. A decade after the Tokyo sarin attack: a review of neurological follow-up of the victims. Mil Med 2007;172:607-10.

7 Kinsley S. Whatever happened to the Kurds? human rights Watch in Iraq. human rights Watch. Available: www.hrw.org/legacy/reports/1991/IRAQ913.htm [Accessed 23 Mar 2018].

8 Snow RL. Deadly cults: the crimes of true believers. Westport, Conn. Praegar, 2003. ISBN: 978-0-275-98952-8

9 Sellstrom A, Cairns S, Barbeschi M. Report of the United nations mission to investigate allegations of the use of chemical weapons in the Syrian Arab Republic on the alleged use of chemical weapons in the Ghouta area of Damascus. Available: https://disarmament-library.un.org/UNODA/Library.nsf/780cfafd472b047785257b10 00501037/e4d4477c9b67de9085257bf800694bd2/\$FILE/A\%2067\%20997-S\% 202013\%20553.pdf [Accessed 23 Mar 2018].

10 Joint Intelligence Organisation. Syria: reported chemical weapons use. Ministry of defence, 2013. Available: https://www.gov.uk/government/uploads/system/uploads/ attachment_data/file/235094/Jp_115_JD_PM_Syria_Reported_Chemical_Weapon_ Use_with_annex.pdf [Accessed 10 Apr 2018].

11 Nauert $\mathrm{H}$. Imposition of chemical and biological weapons control and elimination act sanctions of North Korea, 8. Available: www.state.gov/r/pa/prs/ps/2018/03/279079. htm [Accessed 23 Mar 2018].

12 Prime Ministers Office. Pm statement on the Salisbury investigation. Available: https:// www.gov.uk/government/speeches/pm-statement-on-the-salisbury-investigation-5september-2018 [Accessed 01 Nov 2019].

13 Metropolitan Police. Update on the investigation into the Novichok attack in Salisbury. Available: http://news.met.police.uk/news/update-on-the-investigation-intothe-novichok-attack-in-salisbury-378232 [Accessed 01 Nov 2019].

14 Borkin J. The crime and punishment of I.G. Farben. Mazal holocaust collection. New York: Free Press, 1978. ISBN: 978-0-02-904630-2

15 Organisation for the Prohibition of Chemical Weapons. Nerve agents. Available: https://www.opcw.org/about-chemical-weapons/types-of-chemical-agent/nerveagents/ [Accessed 23 Mar 2018].

16 Stoye E. What we know about Russia's Novichok nerve agents linked to attack on ex-spy, 2018. Available: https://www.chemistryworld.com/news/russian-novichoknerve-agent-linked-to-attack-on-ex-spy/3008773.article [Accessed 23 Mar 2018]. 
17 The Henry L Stimson Center. Chemical weapons disarmament in Russia: problems and prospects. Report No. 17, 19950ctober. Available: www.stimson.org/sites/default/ files/file-attachments/Report17_1.pdf [Accessed 23 Mar 2018].

18 Anon. Union of Soviet socialist Republics-United states: agreement on destruction and non-production of chemical weapons and on measures to facilitate the Multilateral convention on banning chemical weapons. International Legal Materials 1990;29:932-40.

19 Ali J. Chemical weapons and the Iran-Iraq war: a case study in Noncompliance. The nonproliferation review, 2001Spring. Available: https://www.nonproliferation.org/wpcontent/uploads/npr/81ali.pdf [Accessed 19 Apr 2019].

20 Haines DD, Fox SC. Acute and long-term impact of chemical weapons: lessons from the Iran-Iraq war. Forensic Sci Rev 2014;26:97-114.

21 "Halabja, the massacre the West tried to ignore". The Times. [Epub ahead of print: 10 Apr 2019].

22 Tu AT. Aum Shinrikyo's chemical and biological weapons: more than sarin. Forensic Sci Rev 2014;26:115-20.

23 Vale A. What lessons can we learn from the Japanese sarin attacks? Przeg/ Lek 2005;62:528-32.

24 United Nations Security Council. Seventh report of the organisation for the Prohibition of chemical Weapons-United nations joint investigative mechanism. Available:
https://www.securitycouncilreport.org/atf/cf/\%7B65BFCF9B-6D27-4E9C-8CD3 CF6E4FF96FF9\%7D/s_2017_904.pdf [Accessed 16 Nov 2019].

25 NHS England. Hazardous materials (HAZMAT) and chemical, biological, radiological and nuclear (CBRN). Available: https://www.england.nhs.uk/ourwork/eprr/hm [Accessed 24 Apr 2018].

26 Gent N, Milton R, eds. Chemical, biological, radiological and nuclear incidents: clinical management and health protection. public health England. 2nd edn, 2018. https:// assets.publishing.service.gov.uk/government/uploads/system/uploads/attachment_ data/file/712888/Chemical_biological_radiological_and_nuclear_incidents_clinical_ management_and_health_protection.pdf

27 Public Health England. Briefing note for emergency departments - management of suspected Novichok poisonings. Available: https://assets.publishing.service.gov.uk/ government/uploads/system/uploads/attachment_data/file/738497/ED_briefing_ note_nerve_agents.pdf

28 NHS England Emergency Preparedness, Resilience and Response (EPRR). Chemical incidents: planning for the management of Self-presenting patients in healthcare settings. UK government. Available: https://www.england.nhs.uk/ourwork/eprr/hm/\# chemical 